\title{
Psicologia e educação popular: uma estratégia de promoção da
} saúde

\author{
Aline Amaral Sicari', Paola Cecato Pinto' ${ }^{1}$, Larice Santos Silva' ${ }^{1}$ Eliane Regina Pereira ${ }^{2}$
}

\begin{abstract}
Resumo
Neste trabalho, apresentamos uma prática em psicologia da saúde, como parte de um estágio profissionalizante, desenvolvida na sala de espera da Unidade Básica de Saúde de uma cidade mineira. Com base em recortes de três encontros realizados, discutimos a educação popular como um instrumento teórico e prático de educação em saúde na atenção básica. Nesses encontros, objetivávamos a promoção da saúde em rodas de conversa, com a utilização de recursos estéticos como facilitadores e provocadores de discussões. Construir grupos mediante uma postura horizontal foi fundamental para que as reflexões fossem instigadas, as vivências compartilhadas e as verdades instituídas, questionadas.
\end{abstract}

\section{Palavras-chave}

Psicologia em Saúde. Educação Popular. Educação em Saúde. Saúde Coletiva. Promoção da Saúde.

1. Graduadas em Psicologia pela Universidade Federal de Uberlândia. E-mails: alinesicari@hotmail.com; paolacecato@hotmail.com; laricesantos@yahoo.com.br.

2. Doutora em Psicologia pela Universidade Federal de Santa Catarina, professora adjunta I na Universidade Federal de Uberlândia, supervisora de estágios em Psicologia da Saúde no Centro de Saúde Escola Jaraguá e em dois Centros de Referência em Assistência Social de Uberlândia. E-mail: eliane@ipsi.ufu.br. 


\title{
Psychology and popular education: a strategy for health care promotion
}

\author{
Aline Amaral Sicari*, Paola Cecato Pinto*, Larice Santos Silva*, Eliane Regina Pereira**
}

\begin{abstract}
This paper presents a practice in health psychology as part of the professional traineeship carried out in a waiting room of a Primary Health Center (Unidade Básica de Saúde) in a city in Minas Gerais state. Based on three meetings, it is discussed popular education as a theoretical and practical tool for health education in primary care. During these meetings we tried to promote health care through conversations, using aesthetic resources as facilitators and to stimulate discussions. Forming groups in a way everyone could equally participate in the discussions was crucial to encourage reflections, share experiences and question established truths.
\end{abstract}

\section{Keywords}

Health Psychology. Popular Education. Health Education. Public Health. Health Promotion.

* Graduated in Psychology from the Federal University of Uberlândia. E-mails: alinesicari@hotmail.com; paolacecato@hotmail.com; laricesantos@yahoo.com.br.

** Doctor in Psychology from the Federal University of Santa Catarina, professor at the Federal University of Uberlândia, training supervisor in Health Psychology at Centro de Saúde Escola Jaraguá and in two Social Assistance Reference Centers in Uberlândia. E-mail: eliane@ipsi.ufu.br. 


\section{Introdução}

Existir, humanamente, é pronunciar o mundo, é modificá-lo. O mundo pronunciado, por sua vez, se volta problematizado aos sujeitos pronunciantes, a exigir deles novo pronunciar.

Paulo Freire

A ressignificação de um espaço destinado somente à espera traz consigo a potência de encontros entre sujeitos de diferentes lugares, cada qual carregando sua história. A proposta deste trabalho é apresentar um recorte de uma prática de estágio profissionalizante em Psicologia, em que foram desenvolvidos grupos de discussões por meio de rodas de conversa entre sujeitos que estavam no espaço de sala de espera de uma Unidade Básica de Saúde (UBS). Os encontros aconteciam semanalmente, com duração aproximada de uma hora e meia, e foram realizados em duplas de facilitadores, sendo planejados em conjunto com outros estagiários e com a supervisora.

As atividades foram pensadas com o intuito de promover saúde através do compartilhamento de vivências e saberes, provocando reflexões e inspirando novos olhares. Essa forma de construção da prática mostrou-se rica por possibilitar ampliações de ideias e reflexões sobre o que foi e estava sendo feito, permitindo o exercício do diálogo ${ }^{3}$ entre os facilitadores dos encontros. O trabalho em dupla também foi importante porque auxiliou na confecção do registro da prática: enquanto um dos facilitadores foi $\mathrm{o}$ responsável por conduzir o grupo, o outro se ateve às anotações. É válido ressaltar a importância de se registrar os encontros, pois é através deles que refletimos sobre nossas ações e aprendemos com o que foi e com o que não foi feito (DIERCKS; PEKELMAN, 2007).
A prática foi permeada por vários desafios. Um deles esteve no âmbito da própria constituição do grupo para a roda de conversa, o qual era formado sempre por pessoas diferentes que estavam presentes na UBS por terem uma consulta e não por estarem interessadas em participar especificamente de um grupo. Ao mesmo tempo em que essas condições se colocaram como um desafio, a singularidade desse grupo se mostrou como elemento fundamental para pensarmos ações e intervenções que poderiam acontecer nesse espaço coletivo de forma potencializadora.

Outro desafio esteve presente na maneira em que os encontros foram conduzidos, diante da proposta de uma construção coletiva, em que os sujeitos assumiam um papel ativo, de personagens protagonistas na roda, em que não só escutavam, mas também eram ouvidos. Dessa forma, lidávamos diretamente com a fluidez dos temas que surgiam, com as frustrações às expectativas e com a produção de um cuidado horizontal. Nesse sentido, é importante evidenciar que "experienciar" a espontaneidade e a forma de condução do grupo, apesar de ser ferramenta pedagógica da Educação Popular, foi um processo desafiador na prática de estágio.

Tendo como base teórica a Psicologia Histórico-Cultural e utilizando recursos estéticos como disparadores de reflexões, buscamos construir espaços de trocas e de diálogo. Ao pensarmos o homem como um ser que se humaniza a partir de suas relações sociais e das condições em que se encontra, tivemos na atividade em grupo a oportunidade de construir um processo de mediação, que propicia o encontro do sujeito com a realidade, com outros e consigo mesmo (SCHLINDWEIN; SOARES, 2007).

3. Conforme Freire (1980, p. 82-83), o diálogo "é o encontro entre os homens, mediatizados pelo mundo, para designá-lo. Se, ao dizer suas palavras, ao chamar ao mundo, os homens o transformam, o diálogo impõe-se como o caminho pelo qual os homens encontram seu significado enquanto homens; o diálogo é, pois, uma necessidade existencial". 


\section{Educação popular como ferramenta para} a educação em saúde

As práticas tradicionais de cuidado em saúde ainda estão relacionadas a um conceito reducionista de saúde e doença, o qual considera que saúde é apenas ausência de doença, visando técnicas curativas. Diante da necessidade de ampliar o conceito de saúde, colocando-o no âmbito político, pensamos a educação em saúde como uma estratégia fundamental para garantir o redirecionamento das práticas, a promoção da saúde e o olhar integral do sujeito.

A educação em saúde configura-se como um processo que propõe novas formas de agir e produzir a integralidade em saúde, no sentido em que abrange toda a população inserida no seu cotidiano e não apenas em um contexto de adoecimento (MACHADO et al., 2007).

De acordo com Vasconcelos (2004), a educação em saúde tem importância fundamental na construção de vínculos entre o profissional e a população, de forma a estabelecer uma aproximação entre o conhecimento científico e os saberes populares. O mesmo autor evidencia que, inicialmente, os pensamentos sobre educação em saúde estavam atrelados aos interesses de elites políticas que dominavam o país ${ }^{4}$. Através do descontentamento de profissionais da área com os padrões impostos aos serviços de saúde, foi possível emergir pensamentos sobre educação popular, tendo Paulo Freire como referência principal. Mesmo sendo parte dos programas ministeriais de ação em saúde, ainda há dificuldades na execução das práticas de educação em saúde, tanto em relação à postura dos profissionais, quanto ao acesso propiciado pelo serviço. Tradicionalmente, a educação em saúde dá-se de maneira vertical, configurando- se como um instrumento de dominação e de imposição de saberes que em nada colabora para a aproximação dos usuários dos serviços (ALBUQUERQUE; STOTZ, 2004). Em virtude disso, as ações em saúde são predominantemente a favor de uma normatização do que o sujeito deve fazer para prevenir doenças ou solucionar as já existentes (STOTZ, 2007), deixando de lado as realidades sociais que o atravessam, desconsiderando sua singularidade e partindo da ideia de saúde como a ausência de doença. Além disso, o aspecto pedagógico da educação em saúde também se perde. A ideia de que toda ação em saúde é uma ação educativa e de que há uma troca de saberes entre usuário e profissional - movimento importante na formação de pacientes participantes do processo de construção da saúde - fica restrita a momentos específicos das unidades (ALBUQUERQUE; STOTZ, 2004), os quais geralmente são insatisfatórios e pouco atrativos, como os chamados grupos socioeducativos e/ ou informativos, que nem sempre contemplam as demandas dos usuários do serviço e se configuram quase sempre como palestras. Nesse sentido, a educação popular surge como uma alternativa que legitima o conhecimento como um processo de construção coletiva e coloca-se a cargo de introduzir novas práticas nos serviços, visando à valorização do saber do usuário e do profissional como igualmente importantes, a fim de garantir uma maior integralidade de ações (ALBUQUERQUE; STOTZ, 2004).

Para Stotz (2007), a educação popular em saúde é denominada como um movimento social e de luta entre profissionais da área a fim de estabelecer uma construção conjunta de conhecimentos científicos e populares. Partindo de uma concepção de educação

4. Vasconcelos (2004), quando contextualiza a educação em saúde no Brasil, afirma que ela surge a partir dos interesses das elites políticas e econômicas e baseadas em uma lógica de normatização de comportamentos saudáveis. Esse modelo de educação em saúde, somado à falta de investimento em políticas públicas, desencadeou a aproximação dos profissionais e lideranças comunitárias com a educação popular. 
pensada por Paulo Freire, que a considera um instrumento de conscientização, transformação e libertação, a educação popular surge a partir de um trabalho político que abre caminhos para a conquista da autonomia e de direitos (ALBUQUERQUE; STOTZ, 2004).

Ao falarmos em educação popular, pressupomos que seja construída uma relação horizontal entre os facilitadores do grupo e os sujeitos, para que, assim, possamos promover reflexões que perpassam o coletivo e o individual. De acordo com Paulo Freire (2012, p. 85),

[...] não é possível o diálogo entre os que querem a pronúncia do mundo e os que não a querem; entre os que negam aos demais o direito de dizer a palavra e os que se acham negados deste direito. É preciso primeiro que os que assim se encontram negados no direito primordial de dizer a palavra reconquistem esse direito, proibindo que este assalto desumanizante continue.

Ao formar um grupo de promoção da saúde e de educação popular, uma das principais posturas que devemos ter é de "não mais educador do educando, não mais educando do educador, mas educador-educando com educando-educador" (FREIRE, 2012, p. 75). Sendo a atenção básica um ambiente favorável para as práticas de educação em saúde, bem como para educação popular (ALBUQUERQUE; STOTZ, 2004), apresentamos aqui recortes de três encontros, registrados em diário de campo, realizados nessa prática de estágio.

\section{Os encontros na sala de espera}

Os encontros desenvolvidos na sala de espera utilizaram princípios de atuação teórico-práticos em educação popular. Uma característica importante é a metodologia dialógica, que consiste na prática do diálogo como uma maneira de "ouvir o outro, tentar perceberasdiferenças, trabalharessas diferenças"
(DIERCKS; PEKELMAN, 2007, p. 75). Nos vários encontros realizados, essa metodologia se fez presente de forma predominante, por considerarmos importante a escuta aliada a uma tentativa de desconstrução de verdades instituídas e de pontos de vistas enrijecidos. Ainda em relação à metodologia dialógica para a condução de grupos, Diercks e Pekelman (2007) falam sobre a importância das problematizações e da sensibilidade em relação à dimensão cultural para que assim seja possível que os sujeitos falem sobre os aspectos que estão encobertos. Na prática, também percebemos que a utilização dos recursos estéticos abre possibilidades para que os sujeitos possam falar sobre suas experiências singulares a um grupo de desconhecidos e é por meio dessas declarações "escondidas" que enxergamos brechas para evidenciar contradições e promover um pensamento reflexivo. Toda e qualquer ação de educação em saúde deve ter como ponto de partida a necessidade de conhecer a realidade da população com a qual se irá trabalhar diretamente e também compreender as singularidades da unidade de saúde (DIERCKS; PEKELMAN, 2007). Dessa forma, acreditamos que o recurso estético escolhido também deve atender a essa necessidade, pois, por meio desse conhecimento, aumentam-se as possibilidades de construção de sentido dos e pelos participantes. É importante destacar que não existiu a pretensão de afirmar que o recurso estético é o que irá afetar o sujeito, mas sim uma das possibilidades de fazer com que este fale sobre si mesmo.

Os recursos estéticos utilizados nos grupos de sala de espera eram variados. Ao longo dos encontros, utilizamos poemas, fotografias, imagens, músicas, vídeos e objetos definidos como não artísticos. Vázquez (1999, p. 42) nos conta que, "embora para a estética a arte seja um objeto de estudo fundamental, não pode ser exclusivo". Sendo assim, os 
recursos estéticos escolhidos para os encontros não são, necessariamente, considerados arte, mas definidos como recursos que viabilizam um olhar sensível e reflexivo, além de ser algo disparador de conversas e que têm como potência a possibilidade de ampliar as afetações.

A escolha do recurso estético era sempre feita com o objetivo de promover saúde. A decisão sobre qual recurso seria utilizado era feita pelos facilitadores do encontro. A vontade de falar sobre determinado assunto surgia por manifestação dos facilitadores, visto que não há um grupo contínuo, ou seja, não existem demandas específicas do grupo.

Como não existiam assuntos prédefinidos, escolhemos um recurso estético que dá vazão a diversos pensamentos e que possibilita discussões. Temos percebido que as janelas abertas por um recurso estético são sempre maiores do que a que imaginamos e faz do inesperado um processo de educação popular.

\section{Apresentando cenas}

\section{Cena 1: Cortando asas}

Neste dia, utilizamos como recurso estético a imagem de uma criança com asas, as quais pareciam ser cortadas com uma tesoura por dois adultos, um homem e uma mulher. Quando escolhemos esse recurso, tínhamos como ideia principal conversar sobre como a sociedade molda nossos comportamentos, limitando-nos a possibilidade de voar, ou seja, a ideia era estabelecer uma crítica reflexiva.

Uma participantedogrupo, indagadasobre a imagem, começa a falar sobre a importância de cortar as asas das crianças, no sentido de que isso é educação, e formula uma explicação a partir da imagem sobre o comportamento de pais e filhos. A partir desse olhar, por nós inesperado, foi preciso acolher e ampliar o que estava sendo dito e problematizá-lo sem desconsiderar essas impressões provocadas pela imagem.

Facilitadora: O que vocês pensam sobre essa imagem?

Lais $^{5}$ : Os pais querem cortar as asas da criança.

Maria: Para não deixar a criança ficar solta.

Facilitadora: Mas e se tiver uma asa grande? $\mathrm{O}$ que acontece?

Ana: É preciso corrigir, falar os nãos.

Facilitadora: Aparar é diferente de cortar?

Lais: Acho que é igual.

Facilitadora: Cortar as asas é um processo dolorido?

Maria: Dói. É igual cortar a asa do passarinho, dói.

Facilitadora: Será que existe algum incômodo em quem corta as asas?

Débora: Corrigir dói sim. Tem coisa que é difícil, que você acha melhor deixar para lá. É difícil cortar as asas dos filhos quando o assunto são as brigas entre a menor e o maior.

João: Eu sou dependente químico e preciso cortar as minhas próprias asas.

Facilitadora: É interessante esse movimento de cortar a própria asa. Alguém mais aqui precisa fazer isso?

Débora: Eu preciso. Preciso fechar a boca para emagrecer.

Facilitadora: $\mathrm{O}$ movimento de cortar as próprias asas pode ser difícil, mas também pode ser bom, pois pode ser entendido como um movimento de cuidar de si mesmo.

Maria: Preciso cortar as próprias asas para não fumar. É preciso ter um pouco de brilho, brilho na cara para não fumar.

5. Todos os nomes utilizados neste artigo são fictícios e, por se tratar de um relato de experiência, temos a aquiescência da Instituição e dos participantes sobre os registros em diário de campo e o uso das falas em supervisões e publicações científicas. 
Facilitadora: E para parar de fumar é preciso ter apenas brilho?

Maria: Cigarro é um vício muito triste.

Facilitadora: O que vocês pensam sobre isso?

Débora: Deve ser igual a beber e comer excessivamente.

Maria: Controlar isso é muito difícil.

Ana: É difícil controlar a comida e pode ser praticamente um vício, do tipo que tá comendo e sabendo que não pode.

Facilitadora: Será que isso é um desafio? Será que um vício é mais difícil e o outro é mais fácil? [comer excessivamente, dependência química].

Lais: É preciso ter força de vontade.

Facilitadora: Vocês acham que é possível nós mesmos encontrarmos soluções para os nossos problemas?

Ana: É possível, mas difícil.

Facilitadora: Não tem como outra pessoa falar para você parar, afinal a escolha de cada um é particular.

Maria: Eu comecei a fumar com 18 anos e a médica em que fui recentemente falou que tanto faz se eu largar do cigarro ou não.

Lais: Acho que você pode viver mais se você parar.

Ana: Acho que a médica tirou a expectativa que ela tinha.

Facilitadora: Como foi pra você ouvir o que a médica disse?

Maria: [ficou calada].

Ao longo da presente cena, é possível perceber como se dá o movimento de diálogo entre os participantes e como o recurso estético dá margem para uma cadeia de discussões que vão muito além do esperado. A postura de questionamentos assumida pela facilitadora promove a partilha de concordâncias e discordâncias que permitem a ampliação de ideias. Quando compartilhadas, as diferentes formas de pensamento trazem a possibilidade de reformulação de conceitos e uma busca por estratégias para melhor conviver com os problemas cotidianos. De acordo com Vasconcelos (2004), a educação popular em saúde desenvolve pedagogicamente o processo de envolvimento popular dos sujeitos, incentivando uma leitura crítica acerca da realidade, além de ampliar as possibilidades de enfretamentos perante algumas situações cotidianas. Como é possível perceber na cena acima, a análise feita em relação à imagem apresentada produz uma reviravolta no diálogo entre os participantes, uma vez que o tom inicial da conversa destaca o falar do outro e, ao final, os sujeitos falam de si mesmos.

Diercks e Pekelman (2007) escrevem sobre a importância de conhecer a história de vida do sujeito participante do encontro. É interessante perceber que, nessa prática, não é necessário a realização de perguntas específicas para conhecer a vida e o cotidiano das pessoas, pois os relatos biográficos são constantes e acontecem sempre de forma espontânea. Percebemos que muitos participantes, antes de darem suas opiniões sobre os assuntos, contam um pouco sobre sua história de vida e dão exemplos cotidianos que justificam a maneira como pensam e interpretam o mundo. Com isso, podemos perceber que as experiências de cada sujeito os constituem, de forma que a construção de ideias e pensamentos está arraigada às singularidades vivenciadas.

\section{Cena 2: Histórias de vida}

Em um dos encontros da sala de espera utilizamos como recurso estético o poema "No meio do caminho", de Carlos Drummond de Andrade. A escolha foi feita por acreditar que, com esse recurso, seria possível refletir sobre 
as dificuldades, as barreiras e os problemas encontrados na vida, vistos por meio da metáfora da pedra no poema, e possivelmente possibilitar formas de enfrentamento desses momentos e de enxergar possibilidades. Vejamos as falas de Rosana e do marido, Sérgio, e de Nádia, participantes da roda de conversa:

Rosana: Eu estou aqui com meu marido, graças a Deus eu tenho ele. Eu tive câncer, fiquei deprimida e ele me levantou, me deu força. Se não fosse a família ao meu lado, eu teria me suicidado, por isso eu acho que a gente deve valorizar a família.

Nadia: Agora que eu estava num emprego e queria mudar de vida descobri que estou grávida de novo. O primeiro filho foi planejado, mas esse agora não. Toda a minha família mora no Maranhão, me sinto só.

Facilitadora: E o pai da criança, apoia você?

Nadia: Sim, mas trabalha muito e fica pouco em casa. Mas, não quero dizer que a criança é uma pedra, mas, pra ter uma, precisa ter recurso. Deus me deu esse filho pra aumentar a família, só que a gente fica nervosa mesmo no começo, porque esse aqui eu não convivi com o pai dele, mas agora foi uma surpresa.

Amiga de Nadia: Calma, você está preocupada com a gravidez porque não foi programada, mas vai dar tudo certo.

Sérgio [marido de Rosana]: Minha história daria um livro, mas peço desculpas pra vocês porque não vou contar tudo. A Rosana é minha segunda mulher, a primeira faleceu. Eu enfrentei a morte de uma esposa e agora estou doente, preciso lutar para melhorar, mas é preciso tratar e contar com Deus. Eu peço muita graça, e se fosse outra pessoa teria desistido, mas eu sou persistente.

Rosana: Eu era muito vaidosa, eu tinha medo de perder um dedinho. Mas durante o tratamento, tirei um dos seios, sofri e chorei muito por causa disso. Quando eu usava blusas mais apertadas tinha a impressão de que todos estavam olhando para os meus seios. Tem mulher que tem medo de fazer a mamografia e eu também tinha há muito tempo. Aí demorei para fazer o exame com medo do médico ver meus seios, e agora pensem, vergonha é o câncer que você vai dar. O médico já me ofereceu uma prótese pro seio, mas minha resposta é não, se Deus quer assim é porque você mereceu. Cada um deve carregar a cruz recebida.

Facilitadora: Rosana, que interessante a sua história de luta e superação. Mas você já pensou que sua beleza está associada à sua luta, à sua força. A força da mulher que luta pra se recuperar. Você já decidiu não por prótese, mas por você? Ou por Deus? Você já pensou que ele pode desejar que você supere isso também?

Podemos perceber que, em alguns encontros, os participantes levam a discussão para o mesmo caminho que havíamos pensado. É preciso destacar que, para nós, não há discussão certa e/ou errada, qualquer diálogo estabelecido pelo grupo a partir do recurso estético é bemvindo e estará propenso a promover saúde. Nossa proposta baseia-se em uma estética enquanto dimensão sensível, enquanto modo específico de relação com a realidade, pautado por uma sensibilidade que permita reconhecer a polissemia da vida e transcender o caráter prático utilitário da cultura capitalística (ZANELLA, 2006) e das verdades instituídas. Para Vasconcelos (2004), na educação popular em saúde, o diálogo é um dispositivo que proporciona soluções, assim

a educação popular tem significado não uma atividade a mais que se realiza nos serviços de saúde, mas uma ação que reorienta a globalidade das práticas ali executadas, contribuindo na superação do biologicismo, autoritarismo do doutor, desprezo pelas iniciativas do doente e seus familiares e da imposição de soluções técnicas restritas para problemas sociais globais que dominam a medicina atual. É, assim, um instrumento de construção da ação de saúde mais integral e mais adequada à vida da população. (VASCONCELOS, 2004, p. 73). 
Nesse sentido, Diercks e Pekelman (2007) afirmam que o facilitador do grupo deve assumir um conhecimento metodológico profundo para evitar que os encontros fiquem "só no desabafo ou no subjetivismo" (p.78). Neste processo, evidenciamos o papel fundamental do mediador do encontro como o sujeito capaz de dar sentido ao que foi dito durante o grupo, tentando ampliar pontos de vistas a partir de experiências dos sujeitos.

\section{Cena 3: Novos olhares}

Em uma das rodas de conversa realizada, não utilizamos recurso estético para iniciar um diálogo, optamos por fazer questionamentos sobre o serviço de saúde da Unidade, a fim de conhecer o espaço e a maneira como o enxergam. Após levantarmos um questionamento sobre o que é promoção da saúde e sermos respondidos com denúncias do descaso com a saúde pública e com comentários sobre a importância do dinheiro para se obter certos alimentos que levam a uma vida saudável, recebemos então um questionamento. Um dos participantes perguntou:

João: O que é possível fazer pelo dependente químico?

Maria: A família precisa dar apoio, procurar a igreja, pra sair dessa situação.

Facilitador: Dá para conviver com quem diz que controla o uso de drogas?

Maria: Não. O sujeito ainda não entendeu o seu vício.

Facilitador: É importante observar essa situação por diferentes caminhos. Algumas pessoas realmente são dependentes, mas outras pessoas utilizam de drogas sem que isso as atrapalhe. Vício é tudo a mesma coisa? Qual a droga que mais mata?

Muitos respondem: O cigarro.

Facilitador: Então, não apenas as drogas ilícitas causam mal, mas as drogas lícitas, como cigarro e álcool, também podem causar muito mal.

Consideramos que nesse diálogo houve um rompimento de paradigmas e uma pausa para a reflexão acerca de um tema que muitas vezes traz um discurso enrijecido. Nesse contexto, as falas dos facilitadores se revelam em um caminho dialógico, que parte do discurso dos participantes e instiga uma ampliação do olhar e do entendimento sobre o assunto.

No espaço de intervenção em saúde em que ocorria a prática, eram frequentes ações educativas normativas que instituíam verdades dicotômicas, definindo o certo e o errado, o saudável e o prejudicial. Nesse sentido, pensando no recorte exposto acima, Zitkoski (2005) afirma que no conceito de dialogicidade não existe a imposição ou sobreposição de uma opinião sobre outra, pois o diálogo autêntico é nutrido pela flexibilidade ao outro, viabilizando, assim, a chegada de novos elementos, o que vai ao encontro do que é proposto pela educação popular.

Nesse sentido, acreditamos que a educação popular ampara a nossa prática como instrumento de mobilização que se desdobra na possibilidade de organização individual, feita a partir de um exercício coletivo. É a partir do diálogo e do compartilhamento de saberes e experiências, de reações horizontais, que se torna possível a formação de uma postura de resistência e de rupturas.

\section{Considerações finais}

Ao finalizar um dos encontros na sala de espera, sentimos necessidade de esclarecer aos participantes que compreendemos saúde não como ausência de doença, mas de forma ampliada, como um movimento que envolve todas as esferas fisiológicas, psicológicas, 
políticas e sociais que constituem os sujeitos, e que a atividade desenvolvida no estágio era um espaço de promoção da saúde. Essa afirmação é compreendida por muitos como algo novo e os participantes das rodas de conversa mostram-se interessados e questionadores. Por isso, consideramos que as ações desenvolvidas nos grupos de sala de espera são importantes para que os sujeitos que utilizam o serviço de saúde ressignifiquem também o espaço da UBS.

Muitas práticas em educação popular são realizadas com grupos contínuos, em que relações afetivas são construídas processualmente e que os aspectos objetivados nos grupos são percebidos a partir dos encontros. Pensar a sala de espera como um espaço de educação popular não nos permite notar a emancipação e a autonomia no sujeito participante, pois, ao finalizarmos o grupo, não temos qualquer garantia de seu retorno. Esse caráter efêmero da sala de espera a torna ainda mais desafiadora, pois temos a clareza que não promovemos transformações radicais nos sujeitos, mas construímos junto com eles questionamentos e reflexões significativas.

Vasconcelos (2004) afirma que a prática alternativa de educação popular em âmbito nacional está se transformando em uma maneira de reorientar a política de saúde, tornando-se algo estratégico para as ações em saúde pública. Na UBS em que a prática foi realizada, a educação popular ainda não está instituída formalmente, de modo que o enfoque educacional para a saúde é caracterizado somente como algo a mais na unidade. Existem outros grupos com temáticas sobre diabetes, hipertensão, gestação, porém estes são moldados para que o profissional ensine algo para a população, como uma palestra, não existindo uma horizontalidade entre os sujeitos e seus conhecimentos.

Diercks e Pekelman (2007) relatam a importância de uma postura aberta do facilitador perante os questionamentos e as provocações feitas em relação aos saberes que carregamos conosco quando construímos um grupo. Percebemos que, em alguns momentos, o conhecimento científico é transformado em uma verdade absoluta. Assim, reconhecer o saber popular é uma das maneiras de mostrar aos sujeitos que não há "donos" do saber. Por mais que se insista na tentativa de construir uma reflexão conjunta, nos encontros na sala de espera, falas como "e vocês que fazem psicologia, tem solução pro meu caso?" são frequentes, assim como os agradecimentos vindos dos participantes pela "palestra" da sala de espera. Dessa forma, a horizontalidade do conhecimento na roda de conversa é sempre algo a ser alcançado e, mesmo quando conseguimos construir reflexão em conjunto, é necessário realizar reconstruções a partir de falas que ainda colocam o saber científico como o certo.

O espaço do psicólogo no Sistema Único de Saúde (SUS) ainda não é bem definido e muitas de suas práticas se confundem. A lógica de trabalho em promoção da saúde ainda é pouco executada, fazendo com que muitos profissionais psicólogos trabalhem somente no sentido de prevenção e atuem com uma postura clínica tradicional, a qual não se adequa às peculiaridades e às necessidades do serviço público de saúde. De acordo com Albuquerque e Stotz (2004), a falta de atividades de capacitação em educação em saúde afirma essa forma de atuação, sendo que, mesmo quando há tal disponibilidade, há uma falta de apoio das coordenações e secretarias para a execução e o desenvolvimento desse tipo de trabalho.

Diante disso, ocupar o espaço de estagiário em Psicologia em uma UBS foi uma experiência desafiadora, pois o fazer psicológico em saúde coletiva propõe um olhar histórico e social do sujeito, algo que exige uma sensibilidade do profissional. Foi possível perceber, mesmo sob alguns olhares de estranhamento de outros profissionais, que desenvolvemos atividades que demonstraram um possível lugar a ser ocupado.

A relação dialética de trocas de saberes 
e a busca por ações humanizadoras que promovam autonomia aos e com os sujeitos em sua integralidade são aspectos norteadores da nossa prática. Assim, acreditamos que educar em saúde é uma das maneiras de desenvolver um olhar político, ético e humanizado. Nas palavras de Paulo Freire (2012, p. 78): A educação como prática da liberdade, ao contrário daquela que é prática da dominação, implica a negação do homem abstrato, isolado, solto, desligado do mundo, assim como também a negação do mundo como uma realidade ausente de homens. Para o autor, ao mesmo tempo em que o diálogo envolve um pensamento crítico, ele também o produz. Logo, é por meio da prática dialógica que se constrói uma educação emancipatória. Ainda para Freire (2012), a ideia não é salvar os sujeitos das situações em que estão inseridos, mas buscar conhecer a consciência que possuem por serem quem são, de estarem onde estão e as percepções de mundo que fazem a partir dessas consciências. Assim, buscamos em nossa prática promover reflexões sobre o cotidiano, a fim de que os sujeitos repensem as verdades instituídas e possam transformar em inquietações as certezas que os consolam.

\section{Referências}

ALBUQUERQUE, P. C.; STOTZ, E. N. A educação popular na atenção básica à saúde no município: em busca da integralidade. Interface: Comunicação, Saúde, Educação, Botucatu, v. 8, n. 15, p. 259-274, mar./ago. 2004. Disponível em: <http://www.scielo.br/pdf/icse/v8n15/a06v8n15.pdf>. Acesso em: 19 jul. 2013.

DIERCKS, M. S., PEKELMAN, R. Manual para equipes de saúde: o trabalho educativo nos grupos. In: BRASIL, Ministério da Saúde. Secretaria de Gestão Estratégica e Participativa. Departamento de Apoio à Gestão Participativa. Caderno de educação popular e saúde. Brasília: Ministério da Saúde, p. 75-86, 2007. (Serie B. Textos Básicos de Saúde).

FREIRE, P. Educação como prática da liberdade. 10. ed. Rio de Janeiro: Paz e Terra, 1980.

Pedagogia do oprimido. Rio de Janeiro: Nova Fronteira, 2012.

MACHADO, M. F. A. S. et al. Integralidade, formação de saúde, educação em saúde e as propostas do SUS: uma revisão conceitual. Ciência e saúde coletiva, Rio de Janeiro, v. 12, n. 2, mar./ abr. 2007. Disponível em: <http://www.scielo.br/scielo.php?script=sci_arttext\&pid=S141381232007000200009\&lng=en\&nrm=isso > . Acesso em: 12 abr. 2013.

SCHLINDWEIN, L. M.; SOARES, M. L. P. Estética e educação: construindo significado e sentidos a partir de vivências. In: COLÓQUIO DE PSICOLOGIA DA ARTE, 2., 2007, São Paulo. Anais... São Paulo: EDUSP, 2007. p. 1-10.

STOTZ, E. Enfoques sobre educação popular e saúde. In: BRASIL. Ministério da Saúde. Secretaria de Gestão Estratégica e Participativa. Departamento de Apoio à Gestão Participativa. Caderno de educação popular e saúde. Brasília: Ministério da Saúde, p. 46-57, 2007. (Serie B. Textos Básicos de Saúde). 
VASCONCELOS, E. M. Educação popular: de uma prática alternativa a uma estratégia de gestão participativa das políticas de saúde. PHYSIS: Revista Saúde Coletiva, Rio de Janeiro, v. 14, n. 1, p. 67-83, 2004. Disponível em: <http://www.scielo.br/pdf/physis/v14n1/v14n1a05.pdf>. Acesso em: 10 abr. 2013.

VÁZQUEZ, A. S. Convite à estética. Rio de Janeiro: Civilização Brasileira, 1999.

ZANELLA, A. V. "Pode ser flor se flor parece a quem o diga": reflexões sobre educação estética e o processo de constituição do sujeito. In: DA ROS, S. Z.; MAHEIRIE, K.; ZANELLA, A. V. (Orgs). Relações estéticas, atividade criadora e imaginação: sujeitos e(em)experiência Florianópolis: NUP/CED/UFSC, 2006.

ZITKOSKI, J. J. Diálogo em Freire: caminho para a humanização. Revista Eletrônica Fórum Paulo Freire, Pelotas, Ano 1, n. 1, jun. 2005.

Submetido em 23 de setembro de 2013.

Aprovado em 10 de fevereiro de 2014. 